\title{
Advances in machine learning and decision making
}

\author{
Zachary A. Collier ${ }^{1}$. James H. Lambert ${ }^{2} \cdot$ Igor Linkov $^{3}$
}

Published online: 5 August 2019

(c) Springer Science+Business Media, LLC, part of Springer Nature 2019

The September issue of Environment Systems \& Decisions features several articles utilizing advanced machine learning methodologies to derive insights related to chemical toxicity, building energy sustainability, and storm water management. Along with a review paper on nature-based tourism, and two articles describing case studies in scientific risk communication, this issue highlights both the technical and human aspects of decision making necessary for understanding coupled social, environmental, and infrastructure systems.

First, a review article by Mandić (2019) explores the last 10 years of published articles on tourism in protected natural areas. An analysis of the literature uncovers the challenges and opportunities along several dimensions of tourism and ecological management, including governance, conservation, and financing. The findings can be used by those responsible for land management to develop nature-based solutions to mitigate the tensions between ecological, social, and economic priorities.

A series of articles in this issue develop and demonstrate machine learning techniques applied to a variety of domains. Varghese et al. (2019) use natural language processing to classify 7000 abstracts on the topic of arsenic, using an active learning approach to classify the abstracts into categories. The authors explore different sampling techniques on the performance of the machine learning algorithms. Adams et al. (2019) investigate the topic of predicting energy consumption in buildings under faulty and uncertain data. They compare several techniques including random forests and

Zachary A. Collier

zachary@collierresearchsystems.com

James H. Lambert

lambert@virginia.edu

Igor Linkov

igor.linkov@usace.army.mil

Collier Research Systems, Barboursville, VA, USA

2 University of Virginia, Charlottesville, VA, USA

3 US Army Engineer Research \& Development Center, Concord, MA, USA support vector machines with varying levels of data quality to understand the robustness of the predictive results. Amodeo and Francis (2019) apply classification trees to land parcels based on multiple property-level criteria. The results prioritize parcels which may be most suited for low-impact development projects for storm water management.

Finally, in a set of two companion papers, Quigley et al. $(2019 a, b)$ discuss the role of scientific information on riskbased decision making. In the first paper (Quigley et al. 2019a), seven case studies are described, including farming, mining, and natural disaster management. Across these case studies, the authors detail how the various contents and delivery mechanisms of scientific information influenced decision making. The authors describe the different sources of scientific information, and how the absence of scientific information can result in more precautionary alternatives being selected. In the second paper (Quigley et al. 2019b), a synthesis of the findings from the case studies identifies multiple actions and pathways for the acquisition of scientific information and provision of information to the audience. Together, these companion papers will be of value to the scientific and policy communities engaged in using scientific information for decision making and communicating the scientific information to decision makers and the public.

Recently, Google Scholar published their yearly metrics on journal performance. ${ }^{1}$ Environment Systems \& Decisions once again increased its h5-index to 21, up from 18 last year. The h5-median is 30 , and among journals with the word "decision" in the title, Environment Systems \& Decisions is ranked thirteenth. Similarly, Scimago ${ }^{2}$ metrics show an upward trend in areas such as total journal citations, citations per article, and papers with international collaboration among authors. This continued positive trajectory is due to the quality research being submitted by the authors, the constructive feedback from our Editorial Board and peer reviewers, and the technical and operational support of the Springer staff.

\footnotetext{
1 https://scholar.google.com/.

2 https://www.scimagojr.com/.
} 


\section{References}

Adams S, Greenspan S, Velez-Rojas M, Mankovski S, Beling PA (2019) Data-driven simulation for energy consumption estimation in a smart home. Environ Syst Decis. https://doi.org/10.1007/ s10669-019-09727-1

Amodeo DC, Francis RA (2019) Investigating adoption patterns of residential low impact development (LID) using classification trees. Environ Syst Decis. https://doi.org/10.1007/s10669-019-09725-3

Mandić A (2019) Nature-based solutions for sustainable tourism development in protected natural areas: a review. Environ Syst Decis. https://doi.org/10.1007/s10669-019-09718-2

Quigley MC, Bennetts LG, Durance P, Kuhnert PM, Lindsay MD, Pembleton KG, Roberts ME, White CJ (2019a) The provision and utility of science and uncertainty to decision-makers: earth science case studies. Environ Syst Decis. https://doi.org/10.1007/ s10669-019-09728-0

Quigley MC, Bennetts LG, Durance P, Kuhnert PM, Lindsay MD, Pembleton KG, Roberts ME, White CJ (2019b) The provision and utility of earth science to decision-makers: synthesis and key findings. Environ Syst Decis. https://doi.org/10.1007/s10669-01909737-z

Varghese A, Hong T, Hunter C, Agyeman-Badu G, Cawley M (2019) Active learning in automated text classification: a case study exploring bias in predicted model performance metrics. Environ Syst Decis. https://doi.org/10.1007/s10669-019-09717-3 